\title{
Estudio bioquímico del veneno de Tityus kaderkai (Scorpiones: Buthidae) con notas sobre su distribución y hábitat en el Perú
}

\author{
Biochemical study of Tityus kaderkai (Scorpiones: Buthidae) venom with notes on its distribution \\ and habitat in Peru
}

\author{
Enrique Escobar ${ }^{1}$, Rosalina Tincopa ${ }^{1}$ y José A. Ochoa ${ }^{2}$
}

\begin{abstract}
1 Laboratorio de Bioquímica de Toxinas Naturales. Facultad de Ciencias Biológicas. Universidad Nacional Mayor de San Marcos. Apartado 10058, Lima 11, Perú.

Email Enrique Escobar: eescobarg@unmsm.edu.pe

2 Frankfurt Zoological Society - Peru, Residencial Huancaro, Los Cipreses H-21, Santiago, Cusco, Perú.

Email José A. Ochoa: jaochoac2000@yahoo.com
\end{abstract}

Citación:

Escobar E, R. Tincopa y J.A. Ochoa. 2013. Estudio bioquímico del veneno de Tityus kaderkai (Scorpiones: Buthidae) con notas sobre su distribución y hábitat en el Perú. Rev. peru. 20(2): 151 - 158 (Diciembre 2013)

\section{Resumen}

Se ha estudiado bioquímicamente el veneno del escorpión Tityus kaderkai Kovařik, 2005 del departamento de Madre de Dios. El veneno soluble contiene $47.6 \%$ de proteína y por PAGESDS muestra cinco bandas proteicas. Las proteínas del veneno fueron separadas, a partir de $12.9 \mathrm{mg}$ de veneno, mediante cromatografía de intercambio catiónico en CM Sephadex C-25 con buffer acetato de amonio $0.05 \mathrm{M} \mathrm{pH} 7$, obteniéndose 7 picos proteicos (I - VII). Los ensayos de toxicidad han permitido identificar tres toxinas que afectan a Mus musculus y que se encuentran asociadas a los picos IV, $\mathrm{V}$ y VII; asimismo, se ha detectado toxicidad sobre Gryllus sp. en los picos IV, V, VI y VII. Entre las actividades enzimáticas ensayadas, se ha encontrado actividad proteolítica sobre caseína en el pico I y actividad de hialuronidasa en el pico IV con una actividad específica de $205.6 \mu \mathrm{g} / \mathrm{min} / \mathrm{mg}$. Tanto en el veneno soluble como en las fracciones colectadas no se encontró actividad de fosfolipasa, anticoagulante ni hemolítica. El trabajo incluye notas sobre la distribución y el hábitat de la especie.

Palabras claves: veneno; escorpión; toxina; enzima; Tityus kaderkai.

\section{Abstract}

The biochemistry of the venom of Tityus kaderkai Kovařik, 2005 from Madre de Dios department, has been studied. The soluble venom contains $47.6 \%$ of protein. The venom proteins were separated from $12.9 \mathrm{mg}$ of venom using cationic exchange chromatography in CM Sephadex C-25 with a $0.05 \mathrm{M}$ ammonium acetate buffer $\mathrm{pH}$ 7.0. The chromatography profiles show seven peaks of proteins $(\mathrm{I}-\mathrm{VII})$ and five protein bands were distinguished in the crude venom, by PAGE-SDS. The toxicity assays allowed the identification of three toxins affecting Mus musculus which were associated to peaks IV, V and VII. Toxic proteins to Gryllus sp. were also found associated to peaks IV, V, VI and VII. Through the enzymatic activity, the presence of proteolytic activity over casein was found related to the first peak. Hyaluronidase activity has also been found in the peak IV with a specific activity $205.6 \mu \mathrm{g} / \mathrm{min} / \mathrm{mg}$. However, the crude venom and collected fractions did not show any phospholipase, anticoagulant, nor hemolytic activity. Notes on the distribution pattern and habitat are also included.

Keywords: venom; scorpion; toxin; enzyme; Tityus kaderkai.

\section{Introducción}

Los escorpiones son arácnidos venenosos que existen desde hace más de 400 millones de años y cuyas características morfológicas se han mantenido casi inalteradas en el tiempo. Todos ellos son muy activos durante la noche, alimentándose principalmente de insectos, otros artrópodos y en algunos casos de pequeńos vertebrados que atrapan con sus pedipalpos, e inmovilizan o matan con su veneno (Polis 1990). El veneno de escorpión está constituido principalmente por toxinas y enzimas de naturaleza proteica. Estas toxinas actúan sobre el sistema nervioso a nivel de los canales iónicos de sodio, potasio, calcio o cloro, y producen la parálisis de la presa; son los componentes más estudiados porque sirven como excelentes modelos de estructura y función biológica, y también porque son letales a varios organismos incluyendo al hombre. Además, algunas toxinas tienen un potencial uso como sustancias bioinsecticidas o antimicrobianas (Torres-Larios et al. 2000, Pimenta et al. 2001, Jiang et al. 2001, Mejri et al. 2003, 
Bosmans et al. 2005). En relación a las enzimas, se considera que los venenos de escorpiones son pobres en estas proteínas; sin embargo, algunas enzimas han sido detectadas en diversos venenos, entre ellos Heterometrus gravimanus (Pocock, 1894), Heterometrus scaber (Thorell, 1876), Tityus serrulatus Luz \& Mello, 1922 y Tityus bahiensis (Perty, 1833) (Pessini et al. 2001, Almeida et al. 2002, Morey et al. 2006).

El género Tityus C.L. Koch, 1836, contiene 210 especies descritas hasta la fecha y es el grupo más numeroso de la familia Buthidae (Fet \& Lowe 2000, Lourenço 2006). Estos escorpiones se distribuyen en parte de América Central y zonas tropicales de Sudamérica. La toxicidad de sus venenos está relacionada con la presencia de péptidos que afectan los canales iónicos (Barhanin et al. 1982, Becerril et al. 1997). La especie brasilera T. serrulatus, es considerada una de las más peligrosas para el ser humano, y su letalidad se debe a la presencia de toxinas y también a una hialuronidasa que permite la rápida difusión del veneno (Couraud et al. 1982, Pessini et al. 2001).

Otros venenos que se han estudiado son los de Tityus bahiensis (Becerril et al. 1996, Pimenta et al. 2001), T. stigmurus (Torell, 1876), T. cambridgei Pocock, 1897, T. zulianus GonzalezSponga, 1981, T. fasciolatus Pessôa, 1935, T. discrepans (Karsch, 1879), T. trivitattus Kraepelin, 1898 y T. costatus (Karsch, 1879) (Becerril et al. 1996, Batista et al. 2000, 2002; Murguia et al. 2004, Diego-García et al. 2005, Borges et al. 2004, Wagner et al. 2003, D'Suze et al. 2004, Coronas et al. 2003). En estos estudios se han purificado toxinas específicas para artrópodos (D'Suze et al. 2004), insectos (Pimenta et al. 2001) y mamíferos (Borges et al. 1990); en algunos casos también se han encontrado toxinas con acción tanto sobre insectos como mamíferos (Pimenta et al. 2001). Además, también se han reportado algunas actividades enzimáticas como la de hialuronidasa (Pessini et al. 2001) y actividad gelatinolítica (Almeida et al. 2002).

Nuestro laboratorio, desde el año 2002 ha venido trabajando en la purificación y estudio de algunas proteínas de ciertos venenos de escorpiones del Perú tales como los de Hadruroides lunatus (L. Koch, 1867), H. bustamantei Ochoa \& Chaparro, 2008, Centruroides margaritatus (Gervais, 1841) y Brachistosternus ehrenbergii (Gervais, 1841). En estos venenos se han identificado toxinas de naturaleza básica que afectan a Porcelio laevis, Gryllus sp. y Mus musculus. Asimismo algunas enzimas como la fosfolipasa se han encontrado en los venenos de $H$. lunatus, $H$. bustamantei y B. ehrenbergii más no en el veneno de C. margaritatus (Escobar et al. 2002; Escobar et al. 2003a, 2003b, Rivera et al. 2004, Velásquez y Escobar 2004, Ramos y Escobar 2007). Asimismo, ciertos péptidos con acción antibacteriana también han sido descritos (Escobar et al. 2008, Rivera et al. 2010).

En el Perú han sido reportadas 84 especies de escorpiones, siendo el género Tityus representado al menos por 16 especies, distribuidas principalmente en valles interandinos y en la cuenca Amazónica peruana (Ochoa, 2005). Las especies del género Tityus, como ya se mencionó, son particularmente importantes porque muchas de ellas son extremadamente peligrosas para el hombre (Borges 1996, Freire-Maia et al. 1994).

Desde el año 2005, hemos realizado expediciones a diferentes localidades de la Amazonía peruana, registrando varias especies de escorpiones. Entre las especies más abundantes en el departamento de Madre de Dios encontramos a Tityus kaderkai Kovařik 2005, un escorpión conocido hasta ahora sólo para Bolivia. Ejemplares vivos de esta especie fueron llevados al laboratorio donde se procedió a estudiar su veneno, mientras que otros fueron colectados y depositados en el Museo de Historia Natural de la Universidad Nacional de San Antonio Abad del Cusco para su determinación taxonómica.

Este trabajo no solamente representa el primer estudio bioquímico sobre el veneno de una especie del género Tityus en el Perú sino que constituye además, el primer registro de esta especie para el país, ampliando su distribución hasta el sur este peruano en la región Madre de Dios.

\section{Material y métodos}

\section{Material biológico.-}

- Escorpiones de ambos sexos de la especie Tityus kaderkai procedentes de Madre de Dios.

- Ratones albinos Balb/c de 18g.

- Grillos recolectados en la localidad de Huaura, Lima.

- Arañas del género Kukulcania recolectadas en la ciudad universitaria de la UNMSM, para alimentar a los escorpiones.

Recolección y mantenimiento de los escorpiones.- Se utilizaron 79 escorpiones de la especie Tityus kaderkai provenientes del departamento de Madre de Dios, río Los Amigos (12³4'07”S, 7005'57”W, 260 - $280 \mathrm{~m}$, marzo 2005 , J.A.Ochoa \& J.C.Chaparro).

En el laboratorio los escorpiones se mantuvieron juntos en un envase de plástico de 65 × 37 × $30 \mathrm{~cm}$; se les alimentó cada dos semanas con arańas o grillos, y constantemente se les proporcionó algodones humedecidos con agua, de acuerdo al método de Candido y Lucas (2004).

Obtención del veneno.- El veneno, obtenido por estimulación eléctrica con 20 voltios, fue recibido en capilares y depositado en una placa Petri para su desecado al vacío. El veneno se mantuvo a $-18{ }^{\circ} \mathrm{C}$ hasta su uso.

Tratamientos de los ratones.- Los ratones fueron adquiridos en el Instituto Nacional de Salud de Lima y transportados al laboratorio para su uso inmediato en los ensayos de toxicidad. Los procedimientos con los ratones se realizaron de acuerdo con la Guía de manejo y cuidado de animales de laboratorio: ratón del Instituto Nacional de Salud de Lima (Fuentes 2008); y la "ley de protección a los animales domésticos y a los animales silvestres mantenidos en cautiverio" (Ley 27265).

Separación cromatográfica de las proteínas del veneno.Para la separación de las proteínas, $12.9 \mathrm{mg}$ de veneno se disolvieron en $600 \mu \mathrm{L}$ de buffer acetato de amonio $0.05 \mathrm{M} \mathrm{pH} 7$, durante 30 minutos con ayuda de un vortex. Luego se centrífugó a $6000 \mathrm{rpm}$ por 30 minutos y se descartó el precipitado, aplicándose $490 \mu \mathrm{L}$ del sobrenadante a una columna cromatográfica de intercambio catiónico de CM Sephadex C-25 de 13.5 x 1.1 cm equilibrada con buffer acetato de amonio $0.05 \mathrm{M}$ a pH 7.0 (Escobar et al. 2002). Se colectaron fracciones de $1 \mathrm{~mL}$ y las proteínas retenidas en la columna se eluyeron con el mismo buffer conteniendo $\mathrm{NaCl} 0.2 \mathrm{M}$ y 0.6 M. La corrida se realizó a temperatura ambiente y a un flujo de $11 \mathrm{~mL} / \mathrm{h}$.

Cuantificación de proteínas.- Para todos los ensayos el contenido proteico se determinó midiendo la absorbancia a 280 
nm, según el método de Warburg y Christian (1941). Solo para determinar el contenido proteico del veneno soluble se utilizó el método de Lowry et al. (1951).

Electroforesis en gel de poliacrilamida con dodecil sulfato de sodio (PAGE-SDS).- El perfil electroforético del veneno soluble y las fracciones obtenidas se determinaron por PAGESDS de acuerdo al método de Schägger y Von Jagow (1987). Como proteínas estándares se usaron citocromo C $(12.4 \mathrm{kDa})$ y aprotinina $(6.5 \mathrm{kDa})$.

Toxicidad sobre Mus musculus.- Ratones albinos machos de $18 \mathrm{~g}$ de peso fueron inoculados intraperitonealmente con $0,1 \mathrm{~mL}$ de veneno soluble diluido $(7.65 \mu \mathrm{g})$ o de las fracciones colectadas. La toxicidad se evaluó durante 3 horas después de la inoculación, en base a la aparición de ciertos síntomas tales como temblores, hipersalivación, hiperlacrimación, dificultad para respirar, parálisis de extremidades y muerte. En total se realizaron dos ensayos y cada uno por triplicado.

Toxicidad sobre Gryllus sp.- La toxicidad sobre los grillos se evaluó por la inoculación con una jeringa Hamilton, de 5 $\mu \mathrm{L}$ del veneno soluble $(0.22 \mathrm{mg} / \mathrm{mL})$ o $15 \mu \mathrm{L}$ de las fracciones colectadas, en la parte ventral, entre el segundo y tercer par de patas. La toxicidad se determinó por la parálisis o la muerte de los especímenes durante los primeros minutos después de la inoculación.

Actividad de fosfolipasa.- Se determinó por el método de Marinetti (1965), para lo cual se preparó una emulsión de yema de huevo con buffer acetato de amonio 0,05 M pH 7,0 de modo que tuviera una absorbancia inicial a $920 \mathrm{~nm}$ de aproximadamente 0,600 . A $1,5 \mathrm{~mL}$ de esta emulsión se le agregó $100 \mu \mathrm{L}$ del veneno soluble o $10 \mu \mathrm{L}$ de las fracciones colectadas y se midió la disminución en la absorbancia a $920 \mathrm{~nm}$ durante 4 minutos.

Actividad proteolítica.- La actividad proteolítica se determinó sobre caseína, para lo cual se incubó a $37{ }^{\circ} \mathrm{C}, 20 \mu \mathrm{L}$ de caseína $8 \mathrm{mg} / \mathrm{mL}$ con $10 \mu \mathrm{L}$ de la fracción, durante $15,30,60$, 120 y 180 minutos. La evaluación de la actividad proteolítica se realizó por PAGE-SDS (Laemmli, 1970). Asimismo, también se midió la actividad proteolítica sobre albúmina y hemolinfa de grillo. Para esta prueba se mezcló, por separado, $5 \mu \mathrm{L}$ de albúmina bovina $2 \mathrm{mg} / \mathrm{mL}$ o hemolinfa de grillo (diluida 1:3) con $5 \mu \mathrm{L}$ de la fracción con actividad proteolítica. Esta mezcla se incubó a $37^{\circ} \mathrm{C}$ por 90 minutos y la evaluación de la proteólisis se realizó por PAGE-SDS (Laemmli 1970).

Actividad de hialuronidasa.- La actividad de hialuronidasa del veneno soluble y las fracciones colectadas se determinó por turbidimetría según el método de Di Ferrante (1988). La mezcla de reacción contenía $300 \mu \mathrm{L}$ de buffer acetato $\mathrm{pH}$ 6, 100 $\mu \mathrm{L}$ de ácido hialurónico $(0.5 \mathrm{mg} / \mathrm{mL}$ en buffer acetato $)$ y 100 $\mu \mathrm{L}$ de las fracciones colectadas o $30 \mu \mathrm{L}$ de veneno soluble. La mezcla fue incubada durante 20 minutos a $37^{\circ} \mathrm{C}$ y la reacción se detuvo con $1 \mathrm{~mL}$ de bromuro de cetiltrimetilamonio (CTAB) al 2.5\% (diluido en $\mathrm{NaOH} 2 \%$ ). La absorbancia se leyó a 400 nm y la actividad específica se expresó como los microgramos de ácido hialurónico hidrolizados por minuto y por miligramo de proteína.

Actividad hemolítica.- La actividad hemolítica del veneno soluble y de las fracciones colectadas se evaluó en forma directa e indirecta sobre eritrocitos humanos.
Directa.- La mezcla de reacción contenía $200 \mu \mathrm{L}$ de glóbulos rojos al $0.5 \%$ en buffer Tris $0.1 \mathrm{M} \mathrm{NaCl} 0.15 \mathrm{M} \mathrm{pH} 7.5$ y $50 \mu \mathrm{L}$ del veneno soluble o las fracciones colectadas. Se incubó a $37^{\circ} \mathrm{C}$ por 2 horas y después se centrifugó a $6000 \mathrm{rpm}$ por 15 minutos. Finalmente se separó el sobrenadante y se leyó a $541 \mathrm{~nm}$.

Indirecta.- La mezcla de reacción contenía $200 \mu \mathrm{L}$ de glóbulos rojos al $0.5 \%, 25 \mu \mathrm{L}$ de emulsión de yema de huevo (4 veces diluido en buffer Tris $0.1 \mathrm{M} \mathrm{NaCl} 0.15 \mathrm{M} \mathrm{pH} 7.5)$ y $100 \mu \mathrm{L}$ del veneno soluble o las fracciones colectadas. Se incubó a 37 oC durante 2 horas y después se centrifugó a 6000 rpm durante 15 minutos. Finalmente se separó el sobrenadante y se leyó la absorbancia a $541 \mathrm{~nm}$.

Actividad anticoagulante.- La mezcla de reacción conteniendo $100 \mu \mathrm{L}$ de plasma humano citratado y $50 \mu \mathrm{L}$ de veneno soluble o de las fracciones colectadas se incubó a $37{ }^{\circ} \mathrm{C}$ durante 15 minutos. Luego se agregó $50 \mu \mathrm{L}$ de $\mathrm{CaCl}_{2} 0.08 \mathrm{M}$ y se midió el tiempo de coagulación. La actividad anticoagulante se determinó midiendo el retraso en el tiempo de coagulación del plasma, con respecto a un control sin veneno.

\section{Resultados y discusión}

Contenido proteico, separación de las proteínas y PAGESDS.- Para realizar este trabajo se utilizaron $12.9 \mathrm{mg}$ de veneno provenientes de tres extracciones en tres meses sucesivos. En cada extracción se obtuvo 5.7, 4.4 y $2.8 \mathrm{mg}$ de veneno, de 74, 56 y 39 escorpiones respectivamente, obteniéndose en promedio 0.075 mg de veneno por cada escorpión. Adicionalmente, durante las extracciones de veneno, se midió que cada escorpión expulsa en promedio aproximadamente $1 \mu \mathrm{L}$ de veneno.

De acuerdo al método de Lowry, se ha determinado que el veneno soluble de Tityus kaderkai contiene $47.6 \%$ de proteína. En otros venenos de escorpiones de la familia Buthidae se han reportado porcentajes variados de contenido proteico; como por ejemplo, $54.1 \%$ en Buthotus judaicus y $81 \%$ en Centruroides margaritatus (Zlotkin et al.1982, Escobar et al. 2003b).

Luego de pasar el veneno soluble de Tityus kaderkai por la columna de CM-Sephadex C-25 a pH 7 se obtuvo un perfil cromatográfico con siete picos proteicos (del I al VII), de los cuales los tres primeros salieron con el buffer inicial de corrida. $\mathrm{Al}$ agregar $\mathrm{NaCl}$ 0,2 $\mathrm{M}$ eluyeron tres picos adicionales y finalmente con $\mathrm{NaCl} 0.6 \mathrm{M}$ se obtuvo un pico más, tal como se muestra en la Figura 1.

Considerando que a $\mathrm{pH} 7$ este gel está cargado negativamente, debido a los grupos carboximetil que posee, se puede decir que las proteínas de los tres primeros picos tienen igual carga que el gel o son eléctricamente neutras, mientras que las proteínas de los cuatro últimos picos están cargadas positivamente y por ello sólo salen después de aplicar $\mathrm{NaCl}$, quedando en evidencia su naturaleza básica.

Una característica común de los venenos de escorpiones es que la mayoría de sus toxinas son de naturaleza básica, lo cual se tiene en cuenta para separarlas con geles de intercambio catiónico con quienes fácilmente interactúan (Borges et al. 1990). Adicionalmente, la purificación total de estos componentes se obtiene generalmente mediante cromatografía líquida de alta presión (HPLC) en fase reversa.

La PAGE-SDS según el método de Schägger y Von Jagow (1987) mostró la presencia de al menos 5 bandas proteicas en el 


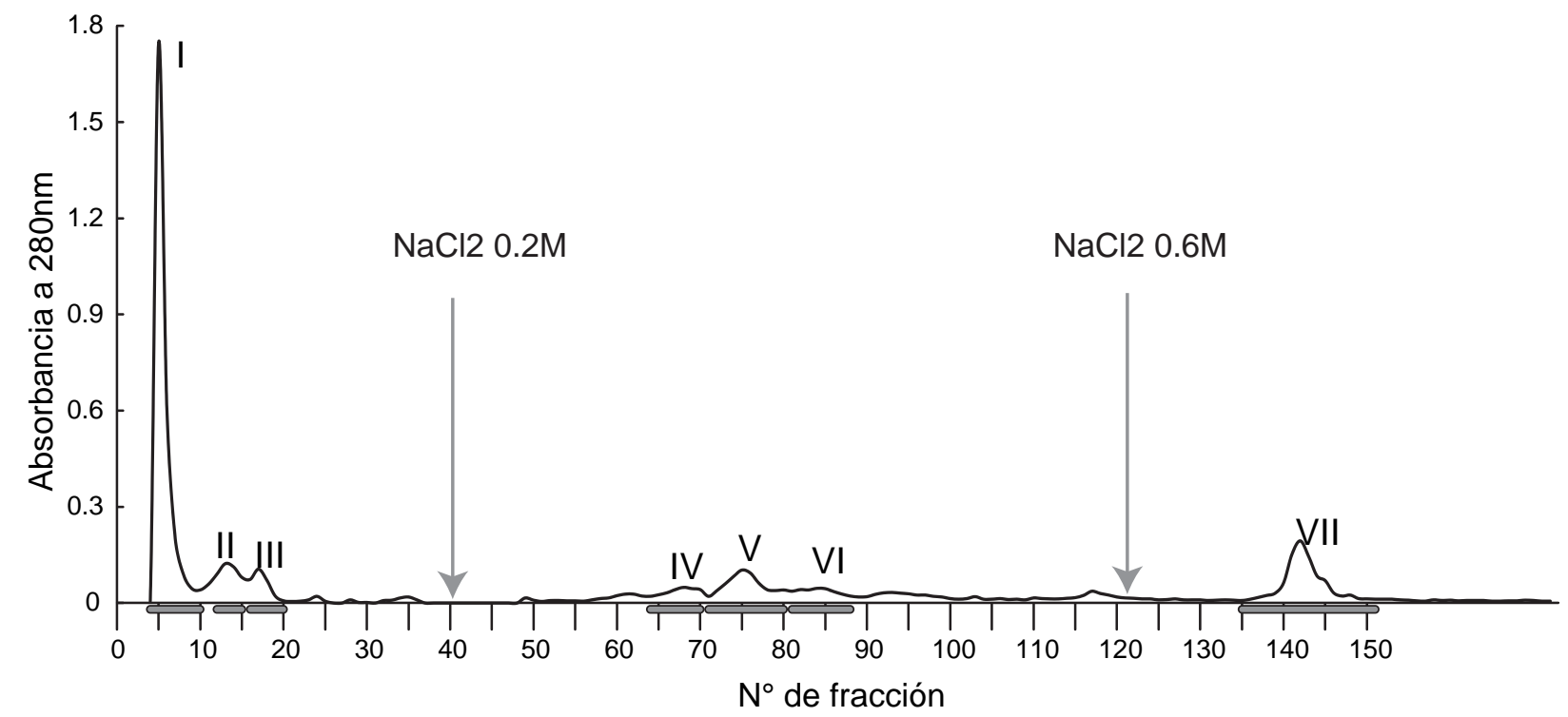

Figura 1. Cromatografía en CM Sephadex C-25. Se aplicó $0.490 \mathrm{~mL}(10.5 \mathrm{mg})$ de veneno soluble de Tityus sp. a la columna de intercambio catiónico $(13.5 \times 1.1 \mathrm{~cm})$ equilibrada con buffer acetato de amonio 0.05M pH 7.0. Se colectaron fracciones de $1 \mathrm{~mL}$. Los números en romanos indican los siete picos de proteína obtenidos.

veneno soluble, de las cuales la de menor peso molecular fue la más gruesa y notoria, lo que indica que la mayoría de proteínas del veneno de Tityus kaderkai son de bajo peso molecular (menor o igual a $6.5 \mathrm{kDa}$ ), lo cual es una característica general de los venenos de escorpiones de la familia Buthidae.

Adicionalmente al analizar electroforéticamente los picos I y IV, se pudo ver que en el pico I se encontraban las bandas proteicas de alto y mediano peso molecular del veneno soluble y en menor medida las proteínas de bajo peso molecular, pero con un patrón muy parecido al del veneno total. En cambio el pico IV mostró una sola banda proteica de $6.5 \mathrm{kDa}$. Los demás picos proteicos no se pudieron analizar electroforéticamente debido a la baja concentración proteica. Estos resultados se pueden ver en la Figura 2 y corroboran el hecho de que los venenos de escorpiones, en general, y los del género Tityus en particular, poseen una gran cantidad de péptidos de bajo peso molecular. Cabe señalar que la única banda proteica correspondiente al pico IV, no necesariamente nos indica que se trata de una sola proteína; lo más probable es que contenga

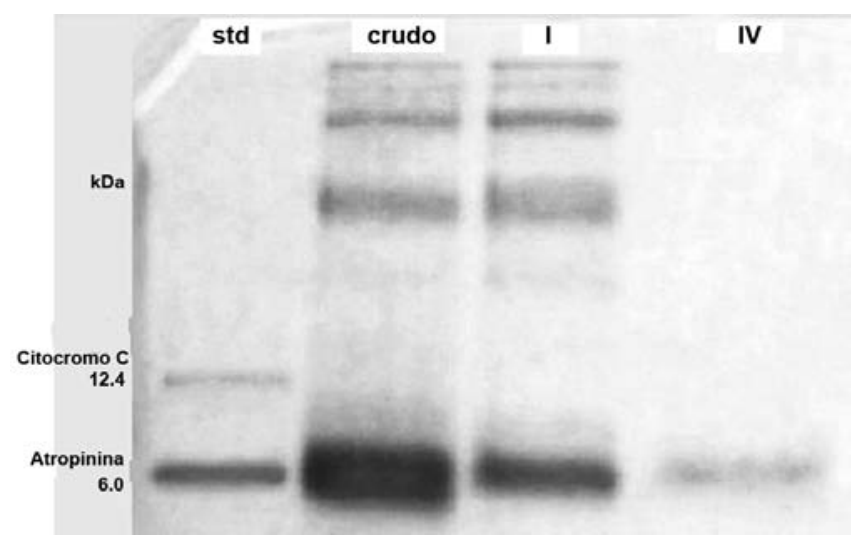

Figura 2. PAGE-SDS del veneno soluble y los picos I y IV. De izquierda a derecha se puede ver el patrón electroforético de las proteínas estándares (std), el veneno soluble, el pico I y el pico IV en los carriles $1,2,3$ y 4 respectivamente. varios tipos de péptidos con diversas actividades pero muy parecidos en el peso molecular. Algo muy ilustrativo al respecto es lo encontrado en otros venenos de escorpiones del género Tityus, como por ejemplo en el veneno de Tityus costatus donde se han encontrado por lo menos 84 componentes de bajo peso molecular (Diego-García et al. 2005).

Toxicidad sobre Mus musculus y Gryllus sp.- La toxicidad sobre Mus musculus se encontró tanto en el veneno soluble como en los picos IV, V y VII de la corrida cromatográfica.

El efecto tóxico del veneno soluble se manifestó por signos de irritabilidad, saltos descoordinados, secreción lacrimal e inmovilidad de las patas posteriores. Asimismo el efecto tóxico del pico IV se evidenció por irritabilidad, exceso de secreción lacrimal y convulsiones, mientras que el pico $\mathrm{V}$ causó hiperactividad e irritabilidad. Finalmente el pico VII produjo pequeños temblores, excesiva salivación y secreción lacrimal, inmovilidad de las patas posteriores y falla respiratoria, muriendo todos los ratones aproximadamente 1 hora después. La muerte producida por el pico VII fue causada con $0.909 \mu \mathrm{g} / \mathrm{g}$ de ratón.

Respecto a la toxicidad sobre insectos, tanto el veneno soluble como las fracciones correspondientes a los picos IV, V, VI y VII, mostraron ser tóxicas en Gryllus sp. La cantidad de proteína que afectó a los grillos fue de $1.1 \mu \mathrm{g}$ en el veneno soluble, y de 0.32 a $1.97 \mu \mathrm{g}$ para las fracciones separadas.

La toxicidad en el insecto se manifestó por la lentitud y descoordinación al caminar, con el cuerpo desplazado hacia un lado, hasta quedar completamente paralizado, todo lo cual se produjo casi inmediatamente después de la inoculación.

El pico VII mostró la mayor toxicidad pues la parálisis producida fue irreversible, en cambio con los otros picos se observó que 10 minutos después de la parálisis algunos grillos empezaban a recuperarse lentamente. El efecto temporal o reversible de estas toxinas no sería contraproducente, ya que igual ellas, como componentes del veneno, cumplirían su función de contribuir a paralizar a la presa. 


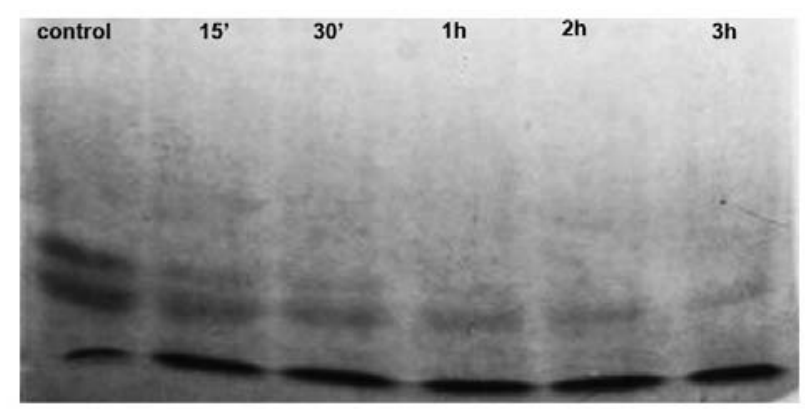

Figura 3. Actividad proteolítica sobre caseína. Desde los 15 minutos de incubación se notó la hidrólisis de la caseína la cual fue más evidente a mayores tiempos de incubación.

Las toxinas de venenos de escorpiones con acción sobre el sistema nervioso han sido ampliamente estudiadas, especialmente en escorpiones de la familia Buthidae, ya que algunos de ellos son letales al hombre. Estas toxinas se caracterizan, al igual que las detectadas en este trabajo, por ser de naturaleza básica y con pesos moleculares entre 6500 y 8500 Da. Su toxicidad se debe principalmente a que son capaces de modular los canales iónicos de sodio operados por voltaje, distinguiéndose las a-toxinas, las cuales se une al sitio 3 del canal y prolongan su inactivación, y las $\beta$-toxinas, las cuales se unen al sitio 4 del canal y aceleran su activación. Entre las a-toxinas, se distinguen toxinas específicas para mamíferos, toxinas específicas para insectos y toxinas con acción sobre mamíferos e insectos (Rodríguez de la Vega y Possani, 2005).

Como ya se indicó, la mayoría de toxinas de esta clase han sido estudiadas en venenos de escorpiones de la familia Buthidae; existiendo sólo una toxina caracterizada en el escorpión Anuroctonus phaiodactylus de la familia Chactidae (Valdez-Cruz et al. 2004). En el caso de escorpiones de nuestro país, toxinas con acción sobre roedores han sido detectadas y parcialmente purificadas a partir de los venenos de Hadruroides lunatus y Brachistosternus ehrenbergii (Escobar et al. 2002, 2003a, Ramos y Escobar 2007).

Según los resultados obtenidos en los ensayos de toxicidad, los picos IV, V y VII afectan tanto a Mus musculus como a Gryllus sp., lo cual muy probablemente se deba a la presencia de toxinas específicas, unas con acción sobre Mus musculus y otras con acción sobre Gryllus sp. Sin embargo, no se descarta la posibilidad de que ambos efectos sean responsabilidad de una misma toxina, tal como se ha indicado mas arriba para el caso de algunas a-toxinas; así por ejemplo, en el veneno de Tityus bahiensis la toxina Tb2-II afecta tanto a mamíferos como a insectos (Pimenta et al. 2001).

Actividades enzimáticas.- Tanto en el veneno soluble como en las fracciones colectadas no se encontró actividad de fosfolipasa. Este resultado coincide con lo reportado para los venenos de Tityus serrulatus, T. bahiensis, T. stigmurus (Venancio et al. 2013), Androctonus crassicauda, Mesobuthus eupeus (Khodadadi et al. 2012) y Centruroides margaritatus (Escobar et al. 2003b), en donde tampoco se ha detectado actividad de fosfolipasa. La fosfolipasa es una enzima que se encuentra ampliamente distribuida en diversos venenos de origen animal, incluído los escorpiones; sin embargo la ausencia de esta enzima parecería ser una característica común no solo de los venenos del género
Tityus, sino una característica general de la familia Buthidae, pues todos los escorpiones arriba mencionados pertenecen a ésta familia. En otros escorpiones como Hadruroides lunatus, Hadruroides bustamantei y Brachistosternus ehrenbergii, que pertenecen a otras familias, sí se ha reportado la presencia de fosfolipasa (Escobar et al. 2002, Velásquez y Escobar 2004, Rivera et al. 2004).

Con respecto a la actividad proteolítica, se encontró que sólo el pico I de proteína mostró actividad enzimática sobre caseína. La evaluación de esta actividad por PAGE-SDS (Laemmli 1970) mostró una hidrólisis progresiva de la caseína en función del tiempo de incubación, la misma que fue evidente desde los 15 minutos de incubación (Fig. 3).

Sin embargo, no se detectó actividad proteolítica sobre albúmina ni hemolinfa de grillo tal como se muestra en la Figura 4, donde se puede ver que el patrón electroforético de la albúmina y de la hemolinfa no variaron por acción de la proteasa del veneno.

De acuerdo a estos resultados se puede concluir que el veneno de Tityus kaderkai posee actividad proteolítica sobre caseína, pero no tiene actividad sobre albúmina ni hemolinfa de grillo.

A diferencia de Tityus kaderkai, los venenos de T. serrulatus y T. bahiensis no tienen actividad proteolítica sobre caseína, pero sí sobre gelatina (medida en geles de poliacrilamida con gelatina incorporada).

Se ha sugerido que las proteasas del veneno podrían actuar como agentes difusores del veneno al incrementar la permeabilidad de los tejidos facilitando así la difusión de las proteínas del veneno; sin embargo la mayoría de venenos de escorpiones carecen de esta actividad lo que indicaría además que los venenos no contribuyen en la digestión proteolítica de la presa. Otra de las hipótesis sobre la función de estas proteasas en los venenos de escorpiones es que modificarían a las toxinas post-traduccionalmente (Almeida et al. 2002). Igualmente es importante señalar que mas recientemente se ha reportado que una metaloproteinasa del veneno de Tityus serrulatus es capaz de hidrolizar a VAMP, una proteína de membrana de vesículas que participa en los procesos de fusión de membranas (Fletcher et al. 2010).

En relación a la actividad de hialuronidasa, esta actividad se encontró en el veneno soluble y en las fracciones correspondien-

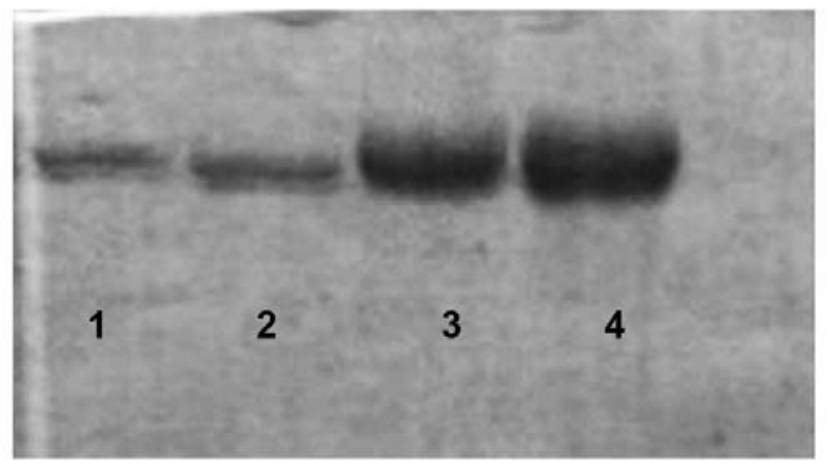

Figura 4. Actividad proteolítica sobre albúmina y hemolinfa de grillo. En los carriles 1 y 3 se muestran los controles de albúmina y hemolinfa, mientras que en los carriles 2 y 4 se muestran los incubados de la albúmina y hemolinfa con la proteasa, respectivamente. Como se puede ver no hay acción proteolítica sobre la albúmina ni la hemolinfa del grillo. 

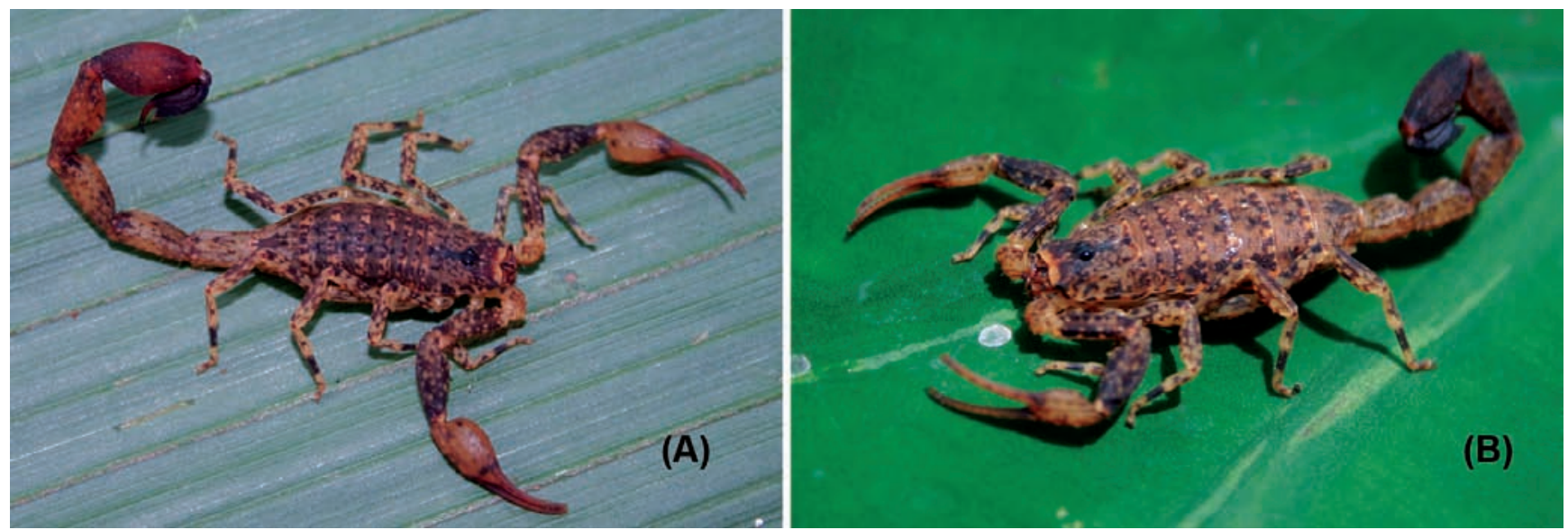

Figura 5. Ejemplares en vivo de Tityus kaderkai Kovařik, 2005, macho (A), hembra (B).

tes al pico IV lo cual nos indica que esta enzima es de naturaleza básica. Luego de la separación cromatográfica, la hialuronidasa se purificó 3,6 veces con un rendimiento de $6.1 \%$. La presencia de hialuronidasa en diferentes venenos se ha asociado con una mayor capacidad de difusión de la ponzońa, debido a que la hidrólisis del ácido hialurónico, un polisacárido muy abundante de la matriz extracelular, permitiría una mayor diseminación de los componentes tóxicos del veneno.

De hecho, se ha demostrado que la toxicidad de los venenos de escorpiones está relacionada al contenido de hialuronidasa, pues la presencia de esta enzima como un factor difusor, hace al veneno más tóxico. Así por ejemplo, en Tityus serrulatus, la hialuronidasa parece ser la responsable de la rápida tasa de absorción que tiene el veneno de esta especie en los tejidos, en comparación a otros venenos del mismo género (Pessini et al. 2001).

Actividad hemolítica y anticoagulante.- Los resultados mostraron que tanto el veneno soluble como las fracciones colectadas carecen de actividad hemolítica directa o indirecta. En algunos venenos de escorpiones se ha visto que la actividad hemolítica directa depende de ciertos péptidos con capacidad de dañar la membrana de los eritrocitos y que en algunos casos muestran también actividad antibacteriana. La actividad hemolítica indirecta se debe a la acción de la fosfolipasa tipo $A_{2}$ que al actuar sobre el fosfolípido, libera un ácido graso más lisolecitina, una sustancia detergente y hemolítica. El hecho que no se haya encontrado actividad de fosfolipasa en el veneno de T. kaderkai, guarda relación con la ausencia de hemólisis indirecta.

La actividad anticoagulante tampoco se encontró en el veneno soluble ni en las fracciones colectadas. La actividad anticoagulante se debe a ciertas proteasas que pueden hidrolizar el fibrinógeno o algún otro factor de coagulación y que por lo tanto afectan la coagulación sanguínea; igualmente algunas fosfolipasas que hidrolizan fosfolípidos que participan en la coagulación de la sangre, también retrasan la coagulación. En este sentido se puede decir que probablemente la proteasa del veneno de Tityus kaderkai no es capaz de hidrolizar ningún factor de coagulación. Cabe indicar que muy pocos venenos de escorpiones tienen actividad anticoagulante, entre los que se puede indicar a Heterometrus gravimanus y Leiurus quinquestriatus (Hamilton et al. 1974).
Notas sobre la distribución de la especie.- Tityus kaderkai fue descrito originalmente para la localidad de Rurrenabaque en el departamento de Beni en el noreste de Bolivia (Kovařik, 2005) siendo hasta la fecha, la única localidad conocida para la especie. Expediciones realizadas en la Amazonía del sureste peruano durante los últimos 8 ańos nos han permitido registrar varias especies de escorpiones de los géneros Bothriurus Peters, 1861, Ananteris Thorell, 1891 y Tityus incluyendo la presencia de T. kaderkai en el departamento de Madre de Dios.

A pesar de la pobre descripción original en el trabajo de Kovařik, el análisis morfológico de los ejemplares de Madre de Dios nos permitió confirmar que son conspecíficos con la especie boliviana. Tityus kaderkai, conocido por los pobladores de la zona como "escorpión moteado" es un escorpión pequeño, de hasta $37 \mathrm{~mm}$ de longitud, siendo los machos ligeramente más grandes que las hembras. La coloración es amarilla ocrácea con pigmentación evidente en todo el cuerpo que le dan una apariencia moteada. La última porción del metasoma es negruzca, y los ejemplares machos poseen el V segmento caudal más abultado que las hembras (Fig. 5).

Esta especie es muy abundante en la Amazonía de Madre de Dios, se encuentra principalmente en bosque secundario, aunque también es posible hallarla en bosque primario. La mayoría de los ejemplares fueron encontrados en la hojarasca (debajo de las hojas o en pequeńas ramitas caídas), pocos individuos estaban trepados en los troncos. Habita entre 250 a 500 m de altitud en localidades pertenecientes a las cuencas de los ríos Alto Madre de Dios, Manu, Madre de Dios, Pariamanu, Los Amigos, Tambopata y en la cuenca del río Heath (Fig. 6).

\section{Literatura citada}

Almeida F., A. Pimenta, S. De Figueiredo, M. Santero, M. Martin-Eauclaire, C. Diniz \& M. De Lima. 2002. Enzymes with gelatinolytic activity can be found in Tityus bahiensis and Tityus serrulatus venoms. Toxicon 40: 1041-1045.

Barhanin J., J. Giglio, P. Léopold, A. Schmid, S. Sampaio \& M. Lazdunski. 1982. Tityus serrulatus venom contains two classes of toxins. Tityus $\mathrm{Y}$ toxin is a new tool with a very high affinity for studying the $\mathrm{Na}^{+}$ channel. Journal of Biological Chemistry 257 (21): 12553-12558.

Batista C., F. Gómez-Lagunas, S. Lucas \& L. Possani. 2000. Tc1, from Tityus cambridgei, is the first member of a new subfamily of scorpion toxin that blocks K+-channels. FEBS Letters 486: 117-120.

Batista C., F. Zamudio, S. Lucas, J. Fox, A. Frau, G. Prestipino \& L. Possani. 2002. Scorpion toxins from Tityus cambridgei that affect $\mathrm{Na}^{+}-$ channels. Toxicon 40: 557-562. 


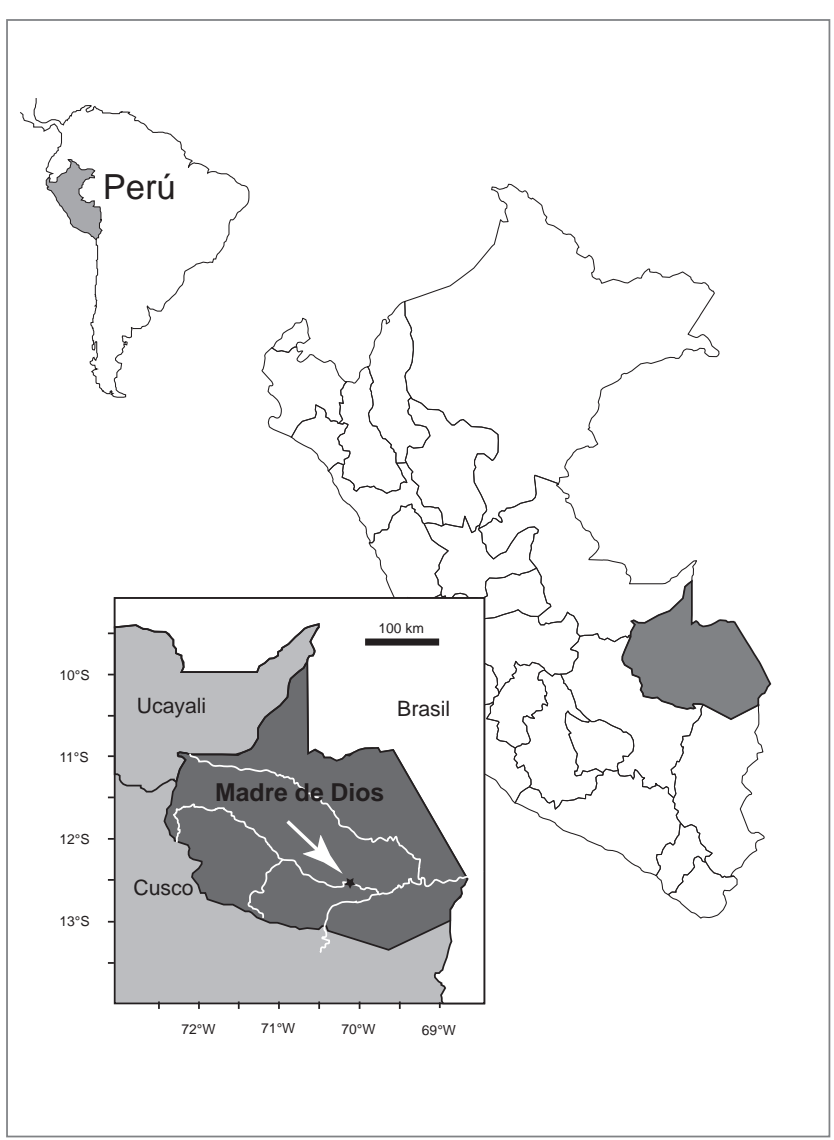

Figura 6. Distribución de T. kaderkai en Madre de Dios. La flecha indica la localidad Los Amigos, de donde proceden las muestras para los estudios de veneno.

Becerril B., M. Corona, F. Coronas, F. Zamudio, E. Calderon-Aranda, P. Fletcher; B. Martín \& L. Possani. 1996. Toxic peptides and genes encoding toxin $y$ of the Brazilian scorpions Tityus bahiensis and Tityus stigmurus. Biochemical Journal 313: 753-760.

Becerril B., S. Marangoni \& L. Possani. 1997. Toxins and genes isolated from scorpions of the genus Tityus. Toxicon 35 (6): 821-835.

Borges A. 1996. Scorpionism in Venezuela. Acta Biol. Venez. 16: 65-76.

Borges A., E. Arantes \& J. Giglio. 1990. Isolation and characterization of toxic proteins from the venom of the Venezuelan scorpion, Tityus discrepans (Karsch). Toxicon 28: 1011-1027.

Borges A., M. Alfonso, C. García, N. Winand, E. Leipold \& S. Heinemann. 2004. Isolation, molecular cloning and functional characterization of a novel $\beta$-toxin from the Venezuelan scorpion, Tityus zulianus. Toxicon 43: 671-684

Bosmans F., M. Eauclaire \& J. Tytgat. 2005. The depressant scorpion neurotoxin LqqIT2 selectively modulates the insect voltage-gated sodium channel. Toxicon 45: 501-507.

Candido D. \& S. Lucas. 2004. Maintenance of scorpions of the genus Tityus Koch (Scorpiones, Buthidae) for venom obtention at Instituto Butantan, Sao Paulo, Brazil. J. Venom. Anim. Toxins incl. Trop. Dis. 10 (1): 86-97.

Coronas F., A. De Roodt, T. Olamendi- Portugal, F. Zamudio, C. Batista, F. Gómez-Lagunas \& L. Possani. 2003. Disulfide bridges and blockage of Shaker B K+-channels by another butantoxin peptide purified from the Argentinean scorpion Tityus trivittatus. Toxicon 41: 173-179.

Couraud F., E. Jover, J. Dubois \& H. Rochat. 1982. Two types of scorpion toxin receptor sites, one related to the activation, the other to the inactivation of the action potential sodium channel. Toxicon 20 (1): 9-16

D’Suze G., C. Sevcik, M. Corona, F. Zamudio, C. Batista, F. Coronas \& L. Possani. 2004. Ardiscretin a novel arthropod-selective toxin from Tityus discrepans scorpion venom. Toxicon 43: 263-272.

Diego-García E., C. Batista, B. García-Gómez, S. Lucas, D. Candido, F. Gómez-Lagunas \& L. Possani. 2005. The Brazilian scorpion Tityus costatus Karsch: genes, peptides and function. Toxicon 45: 273-283.
Di-Ferrante, N. 1956. Turbidimetric measurement of acid mucopolisacharides and hialuronidase activity. J. Biol. Chem. 220: 303.

Escobar E., C. Rivera \& L. Tincopa. 2003a. Acción de la toxina Hl3 sobre músculo esquelético. Rev. peru. biol. 10 (1): 88-92.

Escobar E., C. Rivera, L. Tincopa \& D. Rivera. 2002. Purificación Parcial de las toxinas Hl1, $\mathrm{Hl} 2$ y Hl3 del veneno del escorpión Hadruroides lunatus Koch. 1867 (Scorpionida: Vejovidae). Rev. peru. biol. 9 (1): $3-10$.

Escobar E., L. Flores \& C. Rivera. 2008. Péptidos antibacterianos de los venenos de Hadruroides mauryi y Centruroides margaritatus. Rev. peru. biol. 15(1): 139-142.

Escobar E., L. Velásquez \& C. Rivera. 2003b. Separación e identificación de algunas toxinas del veneno de Centruroides margaritatus (Gervais, 1841) (Scorpiones: Buthidae). Rev. peru. biol. 10 (2): 217-220.

Fet V. \& G. Lowe. 2000. Genus Tityus C.L. Koch, 1836. In: Fet, V., Sissom, W.D., Lowe, G., Braunwalder, M.E. (Eds.), Catalog of the Scorpions of the World, New York Entomological Society, New York, pp. 228-265.

Fletcher P., M. Fletcher, K. Weninger, T. Anderson \& B. Martin. 2010. Vesicle-associated membrane protein (VAMP) cleavage by a new metaloprotease from the brazilian scorpion Tityus serrulatus. The Journal of Biological Chemistry 285 (10) 7405-7416.

Freire-Maia L., J. Campos \& C. Amaral. 1994. Approaches to the treatment of scorpion envenoming. Toxicon 32 (9): 1009-1014.

Fuentes F.M., R.A. Mendoza, A.L. Rosales \& R.A. Cisneros. 2008. Guía de manejo y cuidado de animales de laboratorio: ratón. Instituto Nacional de Salud (Perú). Ministerio de Salud, Instituto Nacional de Salud. Lima. Pp 52.

Hamilton P., D. Ogston \& A. Douglas. 1974. Coagulant activity of the scorpion venoms Palamneus gravimanus and Leiurus quinquestriatus. Toxicon 12 (3): 291-296.

Jiang G., Y. Xu, X. Zhu, Y. Su \& Y. Zhu. 2001. Prokaryotically expressed Buthus martensii Karsch insect depressant toxin has insecticidal effects. Toxicon 39: 469-476.

Khodadadi A., M.H. Pipelzadeh, B. Vazirianzadeh, M. Pipelzadeh \& M. Sharifat. 2012. An in vitro comparative study upon the toxic properties of the venoms from Hemiscorpius lepturus, Androctonus crassicauda and Mesobuthus eupeus scorpions. Toxicon 60: 385-390.

Laemmli U. 1970. Cleavage of structural proteins during the assembly of the head of bacteriophage T4. Nature 227: 680-685.

Ley No 27265. (2000). Ley de protección a los animales domésticos y a los animales silvestres mantenidos en cautiverio. Normas Legales, El Peruano. 22 de mayo de 2000:186915-186917

Lourenço, W. R. 2006. Nouvelle proposition de découpage sous-générique du genre Tityus C. L. Koch, 1836 (Scorpiones, Buthidae). Boletín Sociedad Entomológica Aragonesa, 39: 55-67.

Lowry O., N. Rosebrough, A. Farr \& R. Randall. 1951. Protein measurement with the Folin phenol reagent. Journal of Biological Chemistry $193: 265-275$.

Marinetti G. 1965. The action of phospholipase A on lipoproteins. Biochimica et Biophysica Acta 98: 554-565.

Mejri T., L. Borchani, N. Srairi-Abid, R. Benkhalifa, S. Cestele, I. Regaya, H. Karoui, M. Pelhate, H. Rochat \& M. El Ayeb. 2003. BotIT6: a potent depressant insect toxin from Buthus occitanus tunetanus venom. Toxicon 41: 163-171.

Morey S.S., K.M. Kiran \& J.R. Gadag. 2006. Purification and properties of hyaluronidase from Palamneus gravimanus (Indian black scorpion) venom. Toxicon 47 (2): 188-195. doi:10.1016/j.toxicon.2005.10.014.

Murgia A.R., C.V.F. Batista, G. Prestipino \& L.D. Possani. 2004. Amino acid sequence and function of a new $\mathrm{Q}$-toxin from the Amazonian scorpion Tityus cambridgei. Toxicon 43 (6): 737-740. doi:10.1016/j. toxicon.2004.02.014.

Ochoa J. 2005. Patrones de distribución de escorpiones de la región andina en el sur peruano. Rev. peru. biol. 12(1): 49-68.

Pessini A., T. Takao, E. Cavalheiro, W. Vichnewski, S. Sampaio, J. Giglio \& E. Arantes. 2001. A hyaluronidase from Tityus serrulatus scorpion venom: isolation, characterization and inhibition by flavonoids. Toxicon 39: 1495-1504.

Pimenta A., M. Martin-Euclaire, H. Rochat, S. Figueiredo, E. Kalapothakis, L. Afonso \& M. De Lima. 2001. Purification, amino-acid sequence and partial characterization of two toxins with anti-insect activity from the venom of the South American scorpion Tityus bahiensis (Buthidae). Toxicon 39: 1009-1019. 
Polis G. 1990. The Biology of Scorpions.GA polis. Stanford, California, Stanford University Press, 224-321, 414-445.

Ramos C. \& E. Escobar. 2007. Aislamiento y algunas propiedades de la toxina Be1 del veneno de Brachistosternus ehrenbergii (Gervais, 1841) (Scorpiones: Bothriuridae). Rev. peru. biol. 13 (3) : 243-247.

Rivera C., L. Flores, C. Pantigoso \& E. Escobar. 2010. Aislamiento y caracterización de un péptido antibacteriano del veneno de Centruroides margaritatus. Rev. peru. biol. 17(1): 129-132.

Rivera C.; L. Tincopa; C. Ramos; W. Manya \& E. Escobar. 2004. Estudio preliminar del veneno de Brachistosternus ehrenbergii Gervais, 1841 (Scorpiones: Bothriuridae). Libro de resúmenes de la XIII Reunión Científica ICBAR. p.72.

Rodríguez de la Vega R. \& L. Possani (2005) Overview of scorpion toxins specific for $\mathrm{Na}+$ channels and related peptides: biodiversity, structurefunction relationships and evolution. Toxicon 46: 831-844.

Schägger H. \& G. Von Jagow. 1987. Tricine-sodium dodecyl sulfate-polyacrylamide gel electrophoresis for the separation of proteins in the range from 1 to $100 \mathrm{kDa}$. Anal. Biochem 166: 368- 379.
Torres-Larios A., G. Gurrola, F. Zamudio \& L. Possani. 2000. Hadrurin, a new antimicrobial peptide from the venom of the scorpion $\mathrm{Ha}-$ drurus aztecus. European Journal of Biochemistry 267: 5023-5031.

Velásquez L. \& E. Escobar. 2004. Purificación y caracterización parcial de una toxina $(\mathrm{Hm} 3)$ del veneno de Hadruroides mauryi (Francke y Soleglad, 1980) (Scorpiones, Iuridae). Rev. peru. biol. 11 (2): 153-160.

Venancio E.J., Portaro FC, Kuniyoshi AK, Carvalho DC, Pidde-Queiroz G, Tambourgi DV. (2013). Enzymatic properties of venoms from Brazilian scorpions of Tityus genus and the neutralisation potential of therapeutical antivenoms. Toxicon, 69:180-90. doi: 10.1016/j. toxicon.2013.02.012.

Wagner S., M. Castro, J. Barbosa, W. Fontes, E. Schwartz, A. Sebben, O. Rodrigues, M. Sousa \& C. Schwartz. 2003. Purification and primary structure determination of Tf4, the first bioactive peptide isolated from the venom of the Brazilian scorpion Tityus fasciolatus. Toxicon 41: 737-745.

Warburg O. \& W. Christian. 1941. Isolierüng und kristallisation der garüngs ferments enolase. Biochem. Z. 310: 384-421. 